\title{
Research on the Relationship between Government and Non-profit Organizations in the Age of Social Governance
}

\author{
Zhou Shuang \\ North China Institute of Aerospace Engineering, Hebei, China, 065000
}

Keywords: Cooperative governance; government-non-profit organization cooperative governance; influencing factors

\begin{abstract}
The increase in cooperation between government and non-profit organizations has challenged the management of public administration departments. They not only manage the internal affairs of the organization, but also manage and coordinate affairs across organizations. How to promote and promote cooperation between government and non-governmental organizations has become an urgent problem to be solved. This paper explores this, examines the practice of cooperative governance and analyzes the factors that influence cooperative governance.
\end{abstract}

Many problems have arisen in the rapid development of China's economy, such as employment, social security, income distribution and social security. A large number of social affairs and public problems are beyond the capabilities of the government. The government is no longer omnipotent. The government cannot become the sole administrator of social issues and public affairs and needs the intervention of other entities. The cooperation between the government and non-profit organizations has become a realistic choice.

\section{The need for cooperative governance}

In today's society, with the spread of social power and the blurring of boundaries, many public issues have transcended regional space and the traditional government bureaucracy can't adapt to the requirements of complex and rapidly changing times. The hierarchical bureaucracy follows the command-submission system, the introverted cultural orientation and the "re-execution" characteristics make it difficult to adapt to the needs of cross-sectoral and inter-organizational problem-solving. Population mobility, social diversification and complexity of problems challenge traditional simple problem-solving methods and the universal problem-solving mechanism is replaced by concrete solutions. China in the transition period, complex management objects, backward management methods and means, internal and external relations of change have increased social uncertainty, public issues and social risks. The new social structure and social form mean the inherent requirements for a new order. Economist Hayek believes that the essence of human public affairs is the cooperative order. The cooperative governance of the government and other organizations will be more suitable for the requirements of this new social structure for the new $\operatorname{order}^{[1]}$.

Scholars have given different definitions of the definition of cooperative governance. Scholar 
Chen Hua believes that cooperative governance is a broader cooperation between the government and non-government, non-profit social organizations and even private organizations and the general public in order to achieve the goal of public service. Bardach defines cooperative governance as: "Common activities in which two or more institutions promote shared public values through cooperative, rather than independent, actions". Peters described the connotation of "cooperative governance" as follows: cooperative governance involves two subjects, one of which is the government department; each subject of cooperative governance has the right to argue for their own interests; cooperative governance is a relative Long-lasting and stable relationship; each subject of cooperative governance contributes to the results of cooperation; each subject of cooperative governance must assume responsibility for the results ${ }^{[2]}$.

\section{Government - the logic of cooperative management of non-profit organizations}

\subsection{The advantages of non-profit organizations themselves}

The cooperation between the government and for-profit organizations cannot solve the shortcomings of the market mechanism. The homosexual complex in human nature, the non-profit organization satisfies itself by improving the satisfaction of others, maximizes the effectiveness of its organization and organizational members' personal resources through volunteer activities and participates in social activities, interacts with others and organizes, dedication of the community and the work environment meets the needs of self-realization. This is in stark contrast to the motives and goals of for-profit organizations. The principle of non-distribution of non-profit organizations can guarantee the pursuit of public value by cooperation between government and non-profit organizations to the greatest extent ${ }^{[3]}$. The number of non-profit organizations changes as shown in Figure 1.

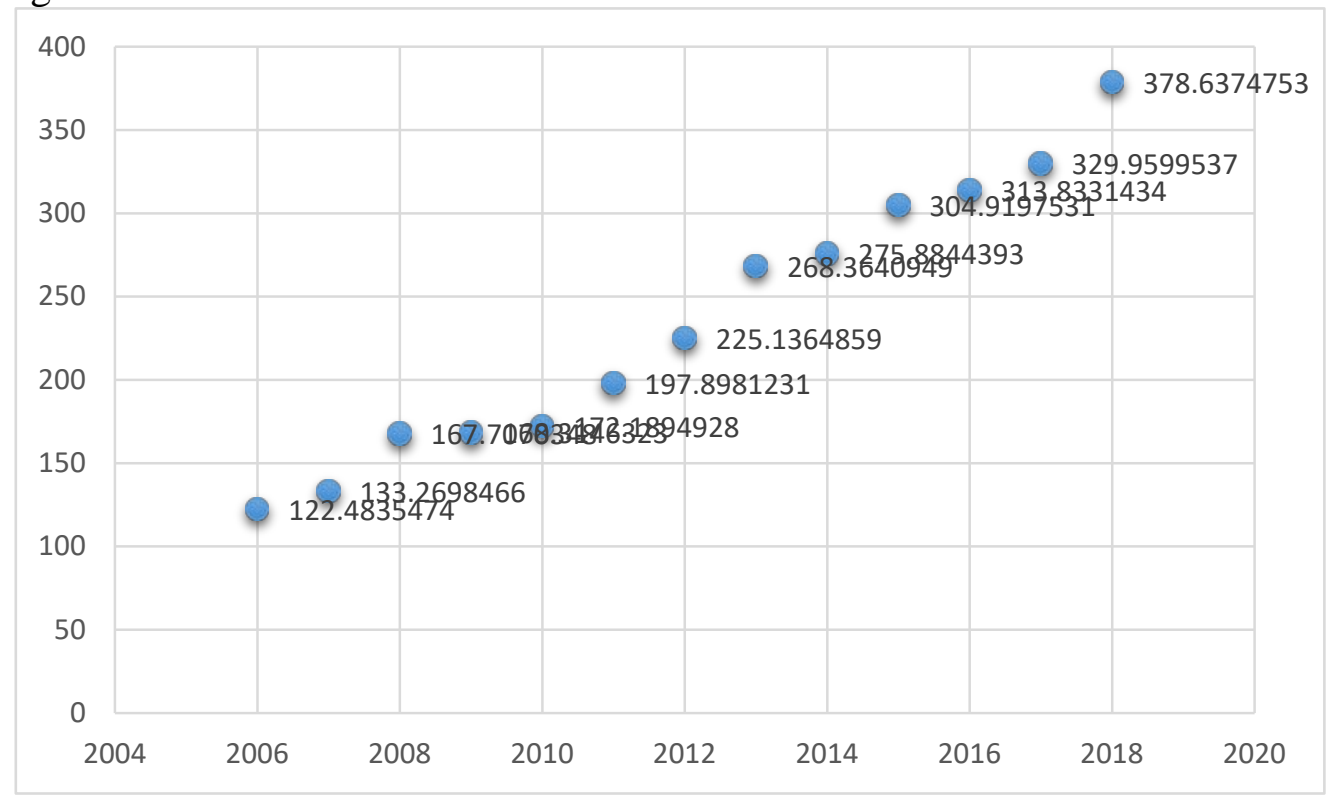

Figure 1 Number of non-profit organizations

\subsection{Government-practical innovation of cooperative governance of non-profit organizations}

The cooperation between the Chinese government and private non-profit organizations began in the 1990s. In 1995, the Shanghai Pudong New Area Social Development Bureau commissioned the Shanghai YMCA to manage the Luoshan Citizens' Club in Pudong New Area, which opened the 
"Roshan Hall" model and broke the previous model of unilateral management by the government. Since 2013, governments in Shanghai, Beijing, Wuxi, Zhejiang and Guangdong have purchased public services from private non-profit organizations, including education, public health and AIDS prevention, poverty alleviation, old-age care, disabled services, community development, community correction and culture., urban planning, civic education, environmental protection, policy advice and other fields. In recent years, with the introduction of new ruling concepts such as scientific development concept and social management, the content of cooperation and governance of Chinese government-non-profit organizations is expanding and enriching, which will effectively alleviate outstanding social contradictions ${ }^{[4]}$.

\section{Cases and analysis}

\subsection{Case: construction of government-non-profit organization partnership}

"Emil" was incorporated in Changsha Civil Affairs Bureau in 2010 and is a private non-enterprise unit. The agency insists on serving the mentally handicapped and is guided by the concept of "helping people to help themselves". Statistics show that by the end of December 2017, "Emile" has provided services for 966 people with intellectual disabilities in education, rehabilitation and employment. At the same time, it has provided capacity building training for 52 civil institutions in Hunan. 120 social work graduates provided supervision services; helped four private institutions in Hunan to receive grants from foundation projects. The results of "Emil" have been widely recognized by the people and the government.

At the beginning of the establishment, "the lack of mutual understanding between the government department and "Emil" did not form the basis of mutual trust. At one time, there was a subtle confrontation. Some government officials even rejected the "Emil", one-sidedly I believe that the civil society organization is looking for the government to obtain funds and materials and ignores the visit of the "Emil". In 2013, the individual leaders of the "Emil" authorities said that "Emile" has incited parents to complain. Suspected and did not pay rehabilitation funds in the same year. When the staff of "Emil" went to the authorities to handle things, they also treated them in a way that they did not see, shirk or simply did not handle them. This made "Emil" and the government in a stalemate ${ }^{[5]}$.

In 2014, Zheng Zeshi starred in "Fat Cat Looking for a Kiss" to Changsha publicity. After learning the news, "Emil" immediately contacted the organizer, hoping to have an interactive activity with Zheng Zeshi and gave him a handmade gift made by a mentally handicapped child, with the consent of Mr. Zheng Zeshi. The meeting will be very enthusiastic. The children are very happy when they see the "fat cat" in their life. They shouted: "Fat cat fat cat I love you, just like mice love rice." Through this activity, Zheng Zeshi saw that Changsha also had institutions for people with intellectual disabilities and was greatly moved. It is proposed that the organizers take the lead in fundraising activities. Seeing this opportunity, "Emil" immediately proposed that in order to increase the influence of the event, I hope to invite relevant government departments to participate. Mr. Zheng Zeshi adopted the proposal of "Emil". In August 2014, a large-scale fundraising party jointly organized by Changsha City's enterprises and media units was held at the Rundu Plaza as scheduled. More than 1,000 people participated in the event. The launch of the event enabled the relevant government departments to understand the "Ai Mier"'s ability to outreach, which naturally eased the relationship with "Emil". Since then, "Emile" has interacted with government departments through regular reporting, regular visits and networking, so that the government can fully understand the work of "Emil".

The government and "Emil" have common good wishes in assisting the socially disadvantaged groups. With this open attitude and acceptance attitude, the interaction between "Emil" and the 
government has also changed and the content is rich and substantial.

\subsection{Case analysis conclusion}

The understanding and views of government departments. Establishing a good government non-profit organization cooperation management must allow government departments to have a correct understanding of the work of non-profit organizations. As China's social problems become more complicated, the government departments are more sensitive to social problems and the concept of social management is deeply rooted in the hearts of the people. Non-profit organizations should make full use of the favorable social public opinion atmosphere, consciously influence the concept of government departments and make government departments Willing to actively seek cooperation with non-profit organizations. The advantages of the government-non-profit organization relationship are shown in Figure 2.

correct understanding of the work of non-profit organizations.
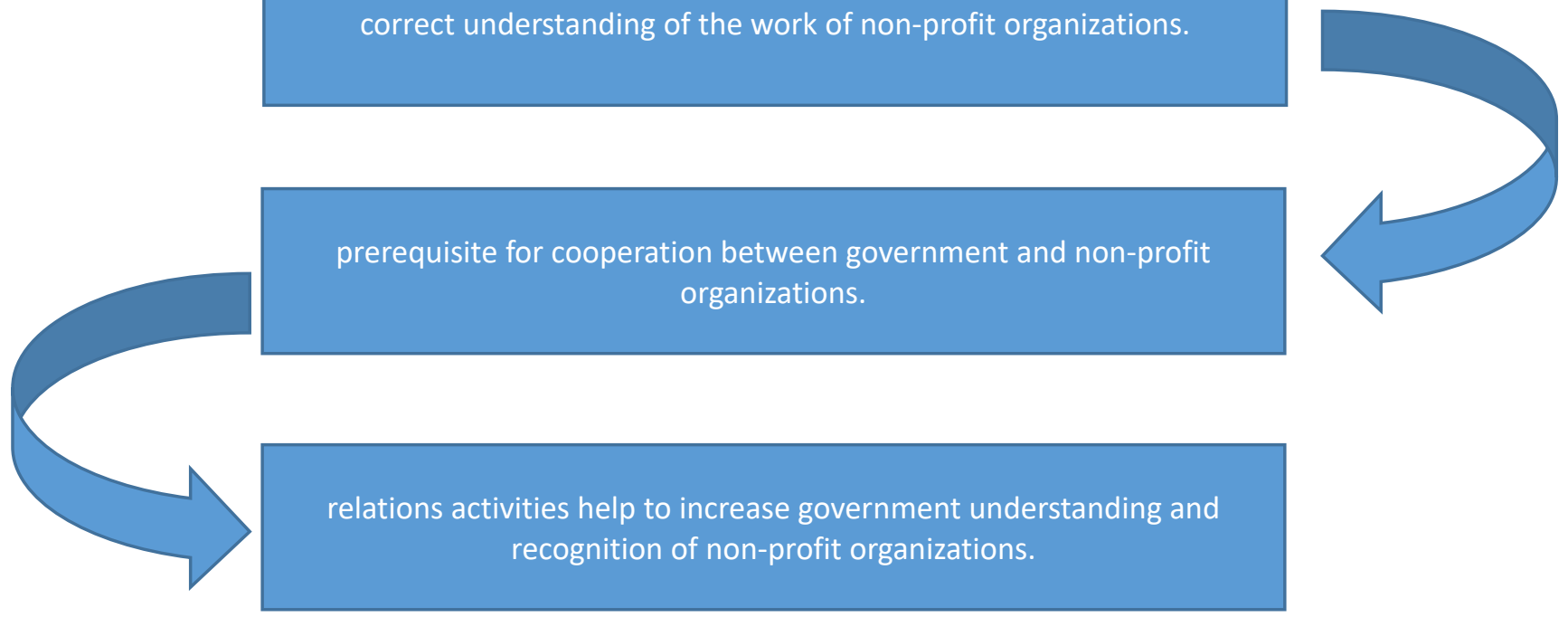

Figure 2 Advantages of the government-non-profit organization relationship

The professional capacity building of non-profit organizations. The improvement of professional competence of non-profit organizations is a prerequisite for cooperation between government and non-profit organizations. The government faces many options in providing public services for public decision-making. The value orientation of government departments is different from that of non-profit organizations. In order to win the support of government departments, non-profit organizations must improve their own capabilities in internal management, finance, human resources and facilities improvement and win the trust and cooperation of the government with professional and effective services.

Public relations construction of non-profit organizations. The public relations activities of Western non-profit organizations began in the 1990s. At that time, many non-profit organizations faced the grim situation of declining donation income and fierce competition and began to think about the development direction of the organization. Non-profit organizations' public relations activities help to increase government understanding and recognition of non-profit organizations. "Emile" has adopted a variety of communication methods to gradually establish a good cooperative relationship with the government, which is crucial for the development of "Emil". In addition, "Emile" also cleverly uses the celebrity effect and social interaction, which increases the social influence of the organization, enables more people to understand and contact the organization and then accepts the organization, expanding the social impact of the organization. The society and the 
government have laid the foundation for accepting these organizations.

\section{Conclusion}

We must see that the cooperation between our government and non-profit organizations has just started. There are many uncertainties or contingency. One incident may cause the cooperation between the two sides to break down. The views of individual government personnel may affect the cooperation between the two sides. However, the lack of government governance capabilities and the rise of new public services around the world require the Chinese government and non-profit organizations to make necessary preparations and move toward cooperative governance.

\section{References}

[1] Soroush Safarzadeh,Morteza Rasti-Barzoki. A game theoretic approach for assessing residential energy-efficiency program considering rebound, consumer behavior, and government policies [J]. Applied Energy, 2018, 233-234.

[2] Soroush Safarzadeh,Morteza Rasti-Barzoki. A game theoretic approach for pricing policies in a duopolistic supply chain considering energy productivity, industrial rebound effect, and government policies [J]. Energy, 2018,167.

[3] Divya Gupta,Tomas M. Koontz. Working together? Synergies in government and NGO roles for community forestry in the Indian Himalayas [J]. World Development, 2018,114.

[4] Henk Berkman,Jonathan Jona,Naomi Soderstrom. Firm value and government commitment to combating climate change [J]. Pacific-Basin Finance Journal, 2018.

[5] M. E. Agwu,H. N. Onwuegbuzie. Effects of international marketing environments on entrepreneurship development [J]. Journal of Innovation and Entrepreneurship, 2018,7(1). 